\title{
Simulation of Fatigue Failure of Rail Joint Bolts by FEA
}

\section{Xiaopeng $\mathrm{Li}^{1, \mathrm{a}}$, Huifan $\mathrm{Nie}^{1}$, Weijie Yuan ${ }^{1}$, and Bangchun Wen ${ }^{1}$}

${ }^{1}$ School of Mechanical Engineering \& Automation, Northeastern University, Shenyang, China

aemail: xpli@me.neu.edu.cn

Keywords: Stress concentrate, Fatigue strength, Temperature force, Bolt torque, Impact

\begin{abstract}
It is well known that the fatigue failure of bolts can affect the performance of rail joint and the safety of train running. In this work, the influence of the bolt torque and radius of rounded root of rail bolt on the fatigue strength of the rail bolt are studied by Finite Element Contact Analysis method. And the influence effects of the wheel impact and temperature force of the rail caused by temperature changed on bolt failure are studied. The results indicate that properly torque and increasing the radius of rounded root rail bolt can reduce the stress concentration at the root of rail bolt and this will improves the fatigue strength and the working life of the rail bolt and rail joint. The repeated temperature force of the rail and wheel impact force are playing an important role in the influencing factors on fatigue failure of the rail joint bolts. Due to this, the two bolts near the rail joints will to be fatigue failure almost earlier than others. That is one of the reasons why the bolts should be preloaded or replaced regularly.
\end{abstract}

\section{The Analysis of Bolt with Finite Element Method}

Finite Element Model of the Bolt. The finite element models of the rail joint bolts are established. According to the national standards, the material of the bolts is 20MnTiB whose Young's modulus is $210 \mathrm{Gpa}$, Poisson's ratio is 0.28 , yield strength is $940 \mathrm{Mpa}$ and tensile strength is $1040 \mathrm{Mpa}$. The geometry dimension of the bolt as follows: the length of bolt bar is $135 \mathrm{~mm}$, the nominal diameter with screw thread is $24 \mathrm{~mm}$, but $22.051 \mathrm{~mm}$ without screw thread, the thread pitch is $3 \mathrm{~mm}$, the screwing length is $24 \mathrm{~mm}$. A computation model was put forward for these bolts [3]. The load distribution along the thread profile will not be influenced by the lead angle which is smaller $4^{0}[4,5]$. When under the axial load, the bolt can be reduced to the axisymmetric problem. To reduce the calculated amount, the axisymmetric model is established as shown in Fig. 1.

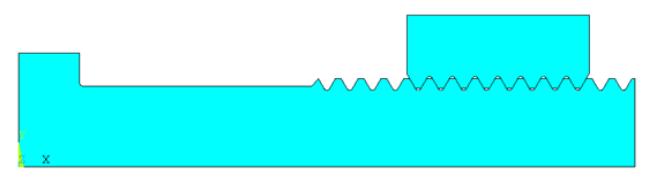

Fig. 1. Bolt geometric model

Element Meshing. The PLANE182 is an axisymmetric and four-node plane element which is suit for analyzing the bolts. To improve the calculation precision and speed, the element size of thread roots with stress concentration should be small, and other part of the bolt should be sparse. Because the bolt and nut are different bodies, the contact area of them should be simulated with contact pair. Considering the actual state, the constraint of Y direction is defined along the bolt's axis and the nut's axis. The constraint of $\mathrm{X}$ direction and the uniform load $\mathrm{P}=188 \mathrm{Mpa}$ are defined in the contact area between bolt and rail splint. The boundary conditions and load conditions as shown in Fig. 2.

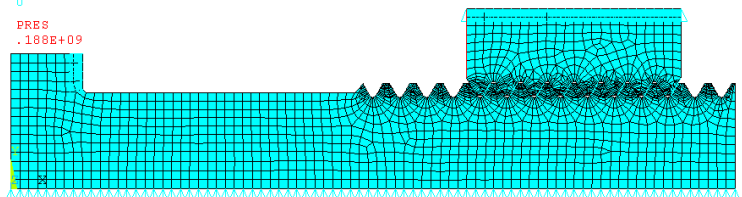

Fig. 2. Boundary conditions and loading of bolts 


\section{Analyze the Results of Simulation}

The Influence on Fatigue Failure of Bolt Caused by the Stress Concentration of the Thread Root. Because of the small fillet radius of the thread root, the section break and stress concentration will occur and excite the fatigue failure of rail joint bolt. In this paper, the finite element models of rail joint bolt with different fillet radius $(0 \mathrm{~mm}, 0.1 \mathrm{~mm}, 0.2 \mathrm{~mm}, 0.3 \mathrm{~mm}$ and $0.4 \mathrm{~mm})$ are established and analyzed. The results about the influence on fatigue failure of bolt caused by stress concentration of thread root are as shown in Fig.3.

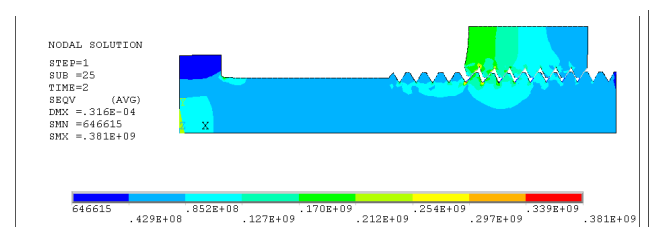

(a) Isoline of equivalent stress with fillet radius $\gamma=0 \mathrm{~mm}$

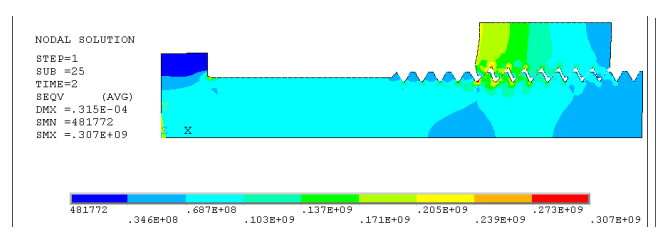

(c) Isoline of equivalent stress with fillet radius $\gamma=0.2 \mathrm{~mm}$

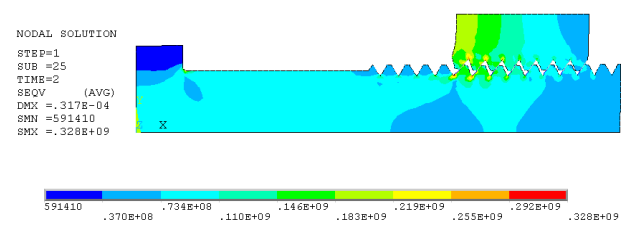

(b) Isoline of equivalent stress with fillet radius $\gamma=0.1 \mathrm{~mm}$

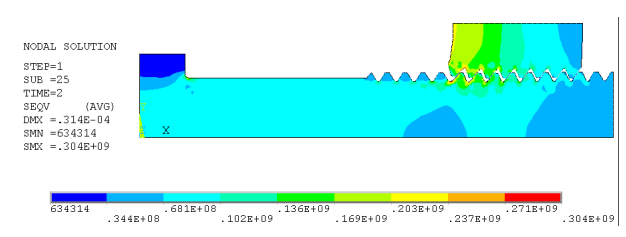

(d) Isoline of equivalent stress with fillet radius $\gamma=0.3 \mathrm{~mm}$

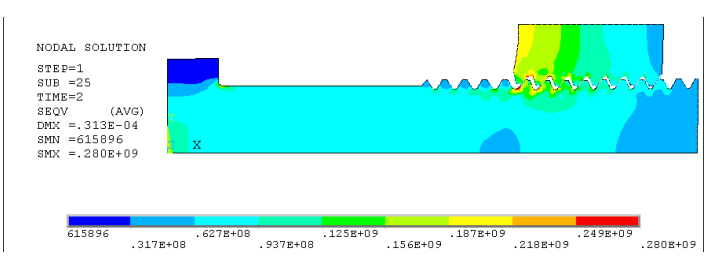

(e) Isoline of equivalent stress with fillet radius $\gamma=0.4 \mathrm{~mm}$

Fig. 3. Different fillet radius analysis results figure

It shows that the threads of the bolt are loaded with non-uniform stress. The stress concentration of thread root is obvious, and the maximum stress exists in the first thread root which connects the nut with the rail splint. The stress will decrease with the increasing distance of thread far away from the loading surface. The positions of the maximum stress are identical with the 65 percent of fracture surfaces occur in bolts. The stress concentration of thread root will rapidly reduces with the increasing fillet radius of the bolt as shown in Fig.4. While the fillet radius increase from $0 \mathrm{~mm}$ to $0.4 \mathrm{~mm}$, the stress of thread root decrease nearly about 26.5 percent from $381 \mathrm{Mpa}$ to $280 \mathrm{Mpa}$.

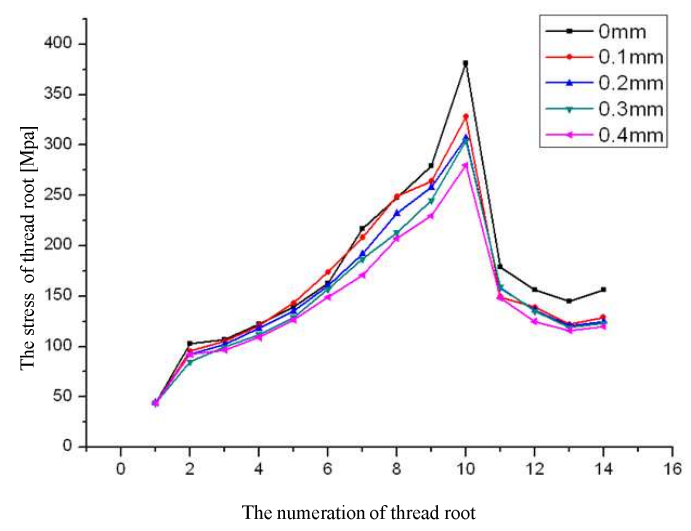

Fig. 4. The comparison chart of stress with different fillet radius 
The Influence on Fatigue Failure of Bolt Caused by Pre-tightening Torque. While the pre-tightening torque of the bolts is unreasonable, the rail gap will be uncontrolled. Then he large rail gap or the blind joint will be formed. The bolts will be snipped or the rail steel will be out of shape respectively. Both of these cases will make the rail joint discontinuous. Because of the large pre-tightening torque, the elastic deformation of the bolt's screw thread will change to be plastic deformation, and the bolt even be twisted. Therefore, it is necessary to analyze and confirm the optimal the pre-tightening torque of the rail joint bolts.

Considering the finite element model as shown in Fig.2, three different pre-tightening torque (400 $\mathrm{N} \cdot \mathrm{m}, 500 \mathrm{~N} \cdot \mathrm{m}$ and $600 \mathrm{~N} \cdot \mathrm{m}$ ) are chosen for the rail joint bolts. According to the equation:

$$
T \approx 0.2 Q_{p} d
$$

The pre-tightening torque $\mathrm{T}$ can be translated to the uniformly distributed load $\mathrm{P}$ as follows: $\mathrm{P}=103.67 \mathrm{Mpa}$, $129.59 \mathrm{Mpa}$ and $155.5 \mathrm{Mpa}$. Then, the three uniformly distributed load $\mathrm{P}$ are respectively defined on the contact area between the nut and supporting plane. The stress and deformation of the bolt are as shown in Fig.5 while considering the influence of the different uniformly distributed load P.

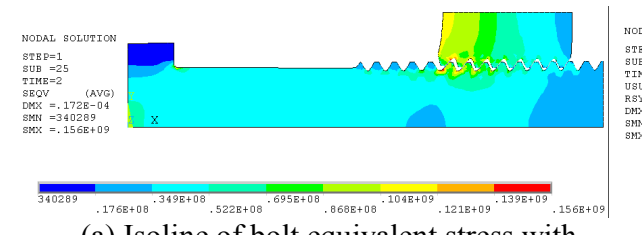

(a) Isoline of bolt equivalent stress with uniform load $P=103.67 \mathrm{Mpa}$

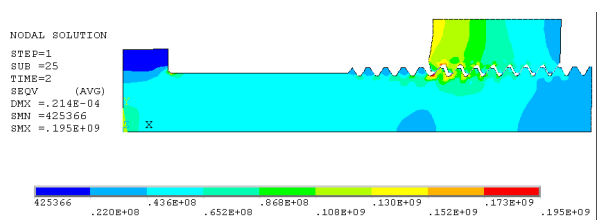

(c) Isoline of bolt equivalent stress with uniform load $\mathrm{P}=129.59 \mathrm{Mpa}$

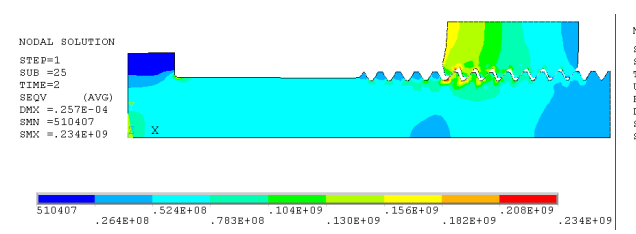

(e) Isoline of bolt equivalent stress with uniform load $\mathrm{P}=155.5 \mathrm{Mpa}$

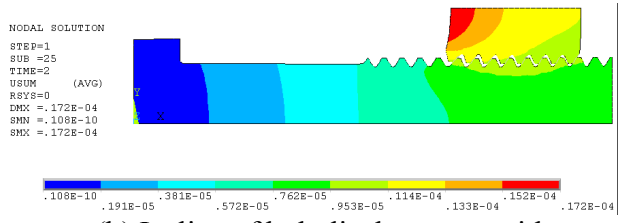

(b) Isoline of bolt displacement with uniform load $P=103.67 \mathrm{Mpa}$

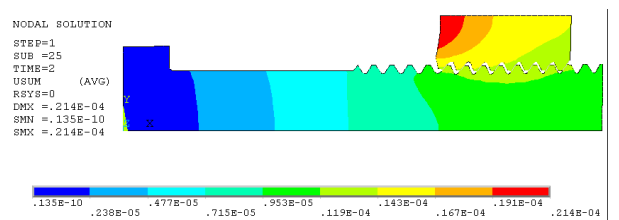

(d) Isoline of bolt displacement with uniform load $\mathrm{P}=129.59 \mathrm{Mpa}$

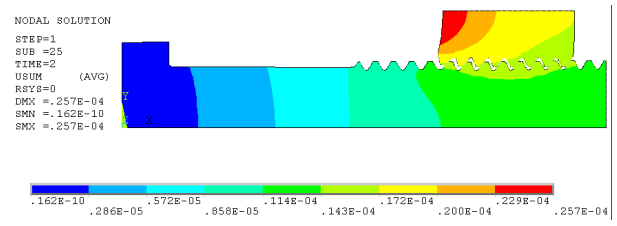

(f) Isoline of bolt displacement with uniform load $\mathrm{P}=155.5 \mathrm{Mpa}$

Fig. 5. Isoline of the equivalence stress and total displacement with different uniform load

The maximum deformations of bolt threads caused by pre-tightening torque as follows: $\varepsilon=0.0107 \mathrm{~mm}, 0.0135 \mathrm{~mm}$ and $0.0162 \mathrm{~mm}$. The local stresses of thread root as follows: $\sigma$ $=156 \mathrm{Mpa}, 195 \mathrm{Mpa}$ and $234 \mathrm{Mpa}$. The results show that the deformation of the bolt will increase with the increasing pre-tightening torque. While the deformation of the thread becomes obvious, the fatigue failure occurs in thread. The stress of thread root is the main factor for the fatigue failure of rail joint bolt. Therefore, reduce the stress of thread root by reasonably controlling the pre-tightening torque is good for prolonging the fatigue life of bolt. According to the Eq. 2, the optimal pre-tightening torque is $807 \mathrm{~N} \cdot \mathrm{m}$.

$$
T_{v}=r_{f} \times F_{v}
$$

\section{The Influence on Rail Joint Bolts Caused by Temperature Force and Train Wheel}

The Influence on Rail Joint Bolts Caused by Temperature Force. Because of the affects of thermal expansion and contraction, the rail steel will expand in summer and contract in winter. And these deformations will be filled with the deformations of the rail joints, which lead to the bolts with 
tensile stress or pressure stress. When these stresses are big enough, the rail steel will be fractured in winter or distort in summer. So, it is necessary to pay more attentions to the temperature force of the rail steel to avoid the overlarge expansion or contraction deformation.

According to long measurement [6], supposing that the highest temperature of the rail steel is $20^{\circ} \mathrm{C}$ higher than the highest ambient temperature, and the lowest temperature is similar to the lowest ambient temperature. Mean temperature difference is $\Delta t=40^{\circ} \mathrm{C}$ in summer and $\Delta t=25^{\circ} \mathrm{C}$ in winter. The temperature force of the rail steel can be calculated based on the equation:

$$
P_{t}=E A \beta \Delta t
$$

The stress and strain of the rail joint bolts caused by temperature force can be worked out with ANSYS Workbench Software Toolkit. As shown in Fig.6.

It shows that when the temperature force is $7.5 \times 105 \mathrm{~N}$ or $4.7 \times 105 \mathrm{~N}$, the maximum equivalent strain is $4.7453 \mathrm{~mm}$ and $3.1123 \mathrm{~mm}$ respectively. And the equivalent stress is $949.06 \mathrm{Mpa}$ and $594.75 \mathrm{Mpa}$ respectively. The expansion and contraction of rail steel will increase with the increasing temperature difference of the rail steel. The bolts will be curved or fractured because of the tensile and shear load that translated by rail splint and rail steel.

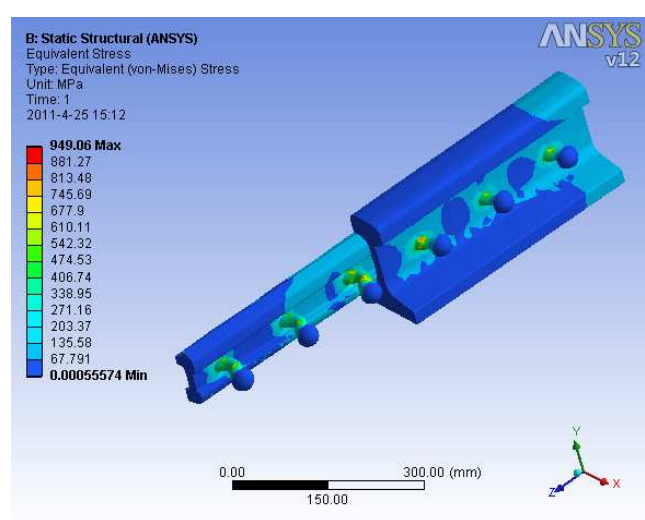

(a) Equivalent stress of rail joint with temperature force $P_{t}=7.5 \times 10^{5} \mathrm{~N}$

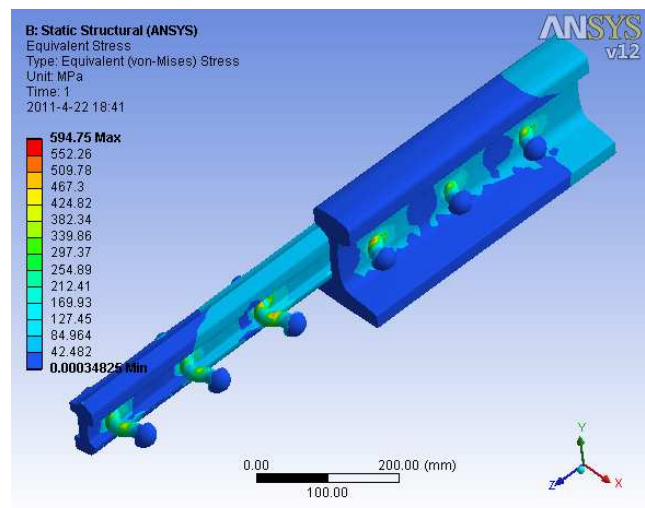

(c) Equivalent stress of rail joint with temperature force $P_{t}=4.7 \times 10^{5} \mathrm{~N}$

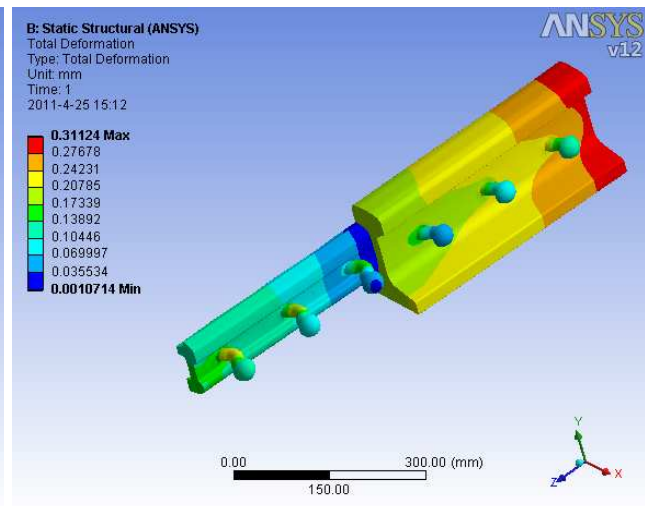

(b) Total deformation of rail joint with temperature force $P_{t}=7.5 \times 10^{5} \mathrm{~N}$

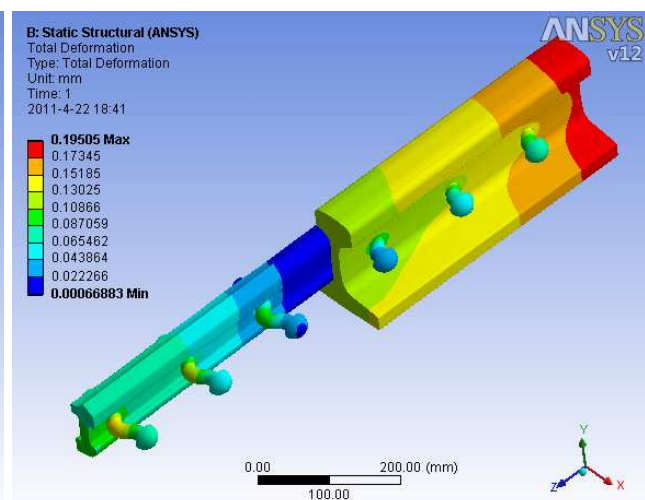

(d) Total deformation of rail joint with temperature force $P_{t}=4.7 \times 10^{5} \mathrm{~N}$

Fig. 6. Isoline of stress and total deformation with different temperature force

The Influence on Rail Joint Bolts Caused by Train Wheel. The vertical force in contact area of the train wheel and rail steel will meet or exceed $200 \mathrm{KN} \sim 250 \mathrm{KN}$ which is determined by the static pressure of the train wheel, the partial dynamic load of the upper springs on the car body and the interaction force between lower springs and rail steel. The additional dynamic load is always $2 \sim 3$ times of the normal vehicle weight. In the worst case, even is $3 \sim 4$ times of the normal vehicle 
weight[7]. In this paper, the influence on rail joint bolts caused by train wheel is researched while the train wheel in two different working conditions. The first working condition: the train wheel is at the right of the rail joint, and $62.5 \mathrm{KN}$ vertical force is loaded on the axis apertures of the train wheel. Then, analyzing the influence on rail steel caused by single train wheel, the results are as shown in Fig.7.

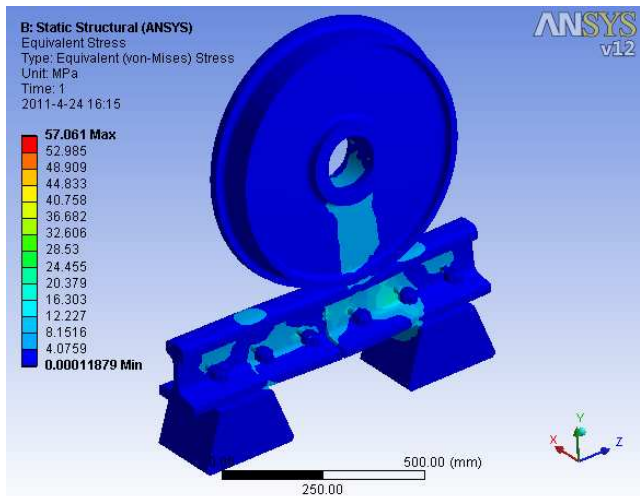

(a) Working condition 1: equivalent stress of rail

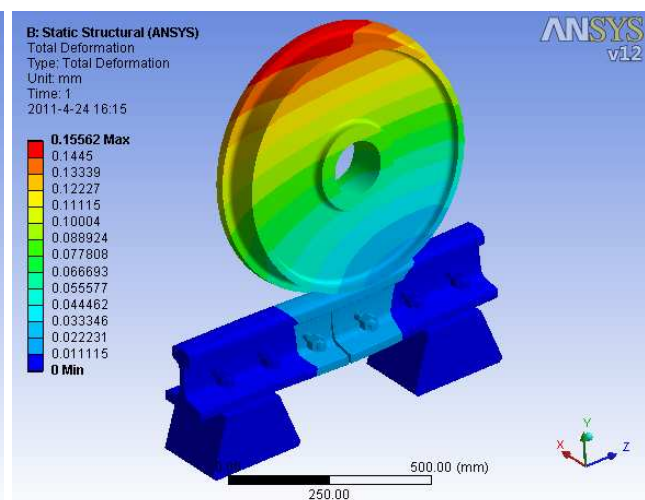

(b) Working condition 1: total deformation of rail

Fig. 7. Working condition 1: total equivalent stress and deformation of rail steel

The second working condition: the train wheel is positioned at the middle of the rail joints, and $187.5 \mathrm{KN}$ vertical force is put on the axis apertures of the train wheel while considering the impact. The results are as shown in Fig.8.

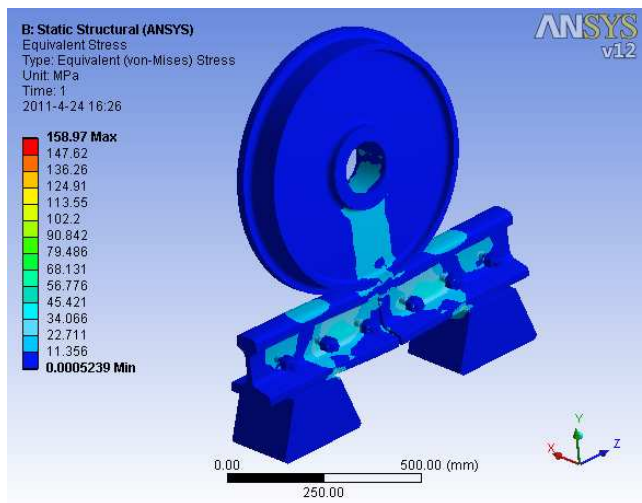

(a) Working condition 2: equivalent stress of rail

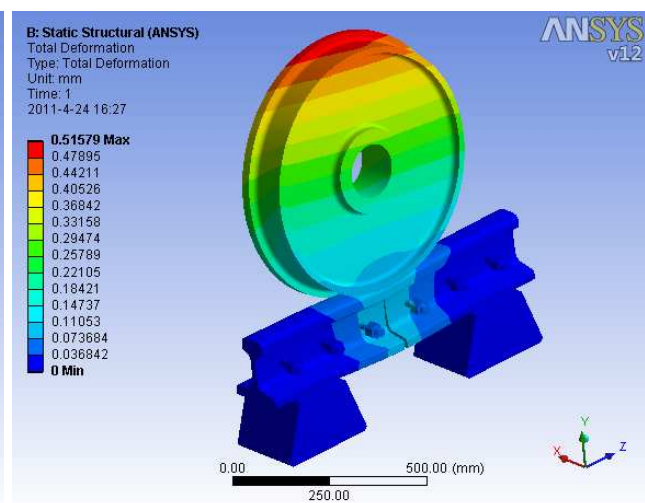

(b) Working condition 2: total deformation of rail

Fig. 8. Working condition 2: total equivalent stress and deformation of rail steel

The bolts are chosen as the measurement volumes with ANSYS Workbench. The stress and strain of the bolts are picked up from the analysis results to research the influence on the bolts caused by the vertical force. The relationship of the serial number, the stress and total deformation of the bolts are as shown in Fig.9 and Fig. 10.

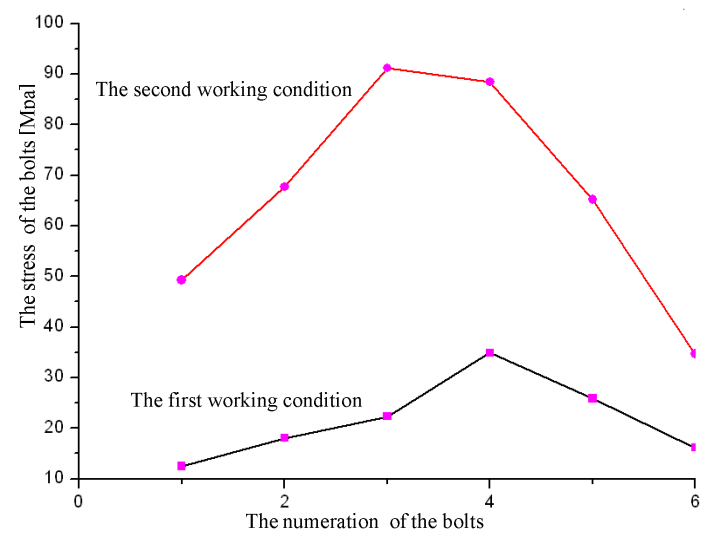

Fig. 9. Relationship between stress and bolt numeration

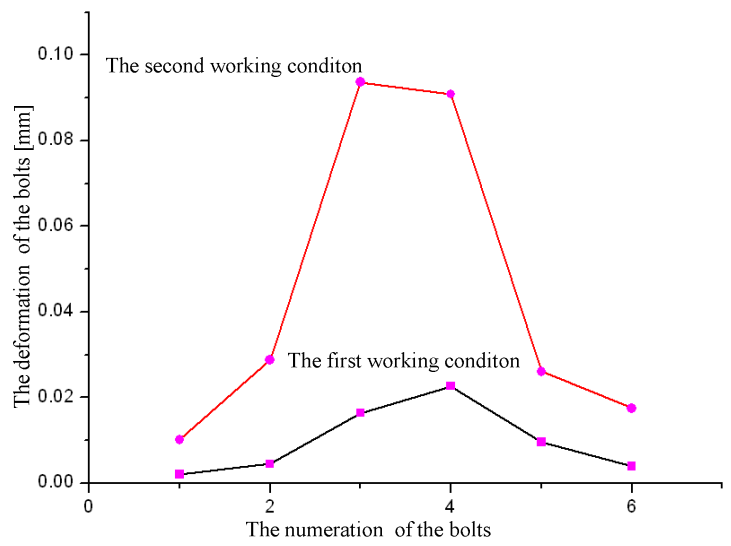

Fig.10 Relationship between deformation and bolt numeration 
It shows that the stress and deformation of the bolts which are closest to the rail joints will be more obvious than other bolts. The stress and deformation of the third bolt and the forth bolt are $3 \sim 4$ times of other bolts. Therefore, they are easier to fatigue failure. The large vertical force caused by train wheel will make the bolts appear obvious stress and deformation. The bolts will appear loose and fatigue failure due to the affects of dynamic loads caused by the changed vehicle weight.

\section{Conclusions}

(1) The stress concentration of thread root is the main factor for the fatigue failure of bolt. The maximum stress exists in the first thread root which is close to the contact area between the nut and the rail splint. And the stress of the other thread roots will decrease gradually. When the fillet radius of the thread root increase from $0 \mathrm{~mm}$ to $0.4 \mathrm{~mm}$, the stress of thread root decrease nearly about 26.5 percent, which is good for avoiding the fatigue failure of bolt.

(2) The deformation of the bolt will increase with the increasing pre-tightening torque. The failure or fracture of the bolt will occur due to the large pre-tightening torque. The optimal pre-tightening torque $T_{y}=807 \mathrm{~N} \cdot \mathrm{m}$ for the rail joint bolt is calculated, which will not lead to large deformation of thread and will prolong bolt's service life.

(3) Because of the temperature force, the maximum equivalent strain of the rail joint bots is $4.7453 \mathrm{~mm}$ in summer and $3.1123 \mathrm{~mm}$ in winter, and the equivalent stress is $949.06 \mathrm{Mpa}$ and 594.75Mpa respectively. If the equivalent strain and equivalent stress large enough, the bolts will be curved or fractured.

(4) When the train wheel is positioned at the middle of the rail gap(the second working condition), the stress and deformation of the bolts are 3 4 times of those bolts which in the first working condition that the train wheel is positioned at one side of the rail joint. The stress and deformation of the two bolts near the rail joint are maximums. The bolts will appear loose, even fatigue failure because of the affects of dynamic loads caused by the changed vehicle weight.

\section{Acknowledgements}

This paper is supported by Program for New Century Excellent Talents in University (NCET-10-0301), and the Fundamental Research Funds for the Central Universities (N090403004).

\section{References}

[1] Toshimichi Fukuoka, Evaluation of the Method for Lowering Stress Concentration at the Thread Root with Modifications of Nut Shape, J. Proceedings of JSME. (1994) 51-59.

[2] Zhang Jiaxu, Han Bangfei, Zhang Buoqing, Study of the Factors Affecting the Bearing Capacity of High-strength Bolts, J. Shijiazhuang Railway Institute, 2, 9 (1996) 81-87.

[3] Xu Suyang, Bai Weiwei, Miao Dehua, Theoretical Analysis and Test of Ordinary Bolt Used on Anti-fatigue Rail, J. Engineering \& Test. 4 (2009) 31-33.

[4] Zhao Hua, Analysis of the load distribution in a bolt-nut connector, J.Computer and Structures. 53 (1944) 1465-1472.

[5] Piao Yan, Design and calculation of threaded connection, Higher Education Press., Beijing, 1995.

[6] Cheng Li, Long Mengqiu and Mao Bixian, Railway Line and Railway Signal, Southwest Jiaotong University Press., Chengdu, 2004.

[7] Zhang Zeng, How to eliminate the defect of the battered joint of rail, J. Railway Construction. 6 (1945) 39-40. 